\title{
Evaluation of the Guidelines for Penile Cancer Treatment: Overview and Assessment
}

\author{
Abdulmajeed Aydh, ${ }^{1,2}$ Shahrokh F. Shariat, ${ }^{凶 1,3,4,5,6,7,8,9}$ Reza Sari Motlagh, ${ }^{1}$ Ekaterina Laukhtina, ${ }^{1,9}$ \\ Fahad Quhal, 1,10 Keiichiro Mori, ${ }^{1,11}$ Hadi Mostafaei, ${ }^{1,12}$ Andrea Necchi,, ${ }^{13}$ Benjamin Pradere ${ }^{1,14}$ \\ ${ }^{1}$ Department of Urology, Comprehensive Cancer Center, Medical University of Vienna, Vienna, Austria ${ }^{2}$ Department of Urology, King Faisal Medical City, \\ Abha, Saudi Arabia ${ }^{3}$ Department of Urology, Weill Cornell Medical College, New York, United States ${ }^{4}$ Department of Urology, University of Texas Southwestern, Dallas, \\ United States ${ }^{5}$ Department of Urology, Second Faculty of Medicine, Charles University, Prague, Czech Republic ${ }^{6}$ European Association of Urology Research Foundation, \\ Arnhem, Netherlands ${ }^{7}$ Karl Landsteiner Institute, Vienna, Austria ${ }^{8}$ Division of Urology, Department of Special Surgery, Jordan University Hospital, The University of \\ Jordan, Amman, Jordan ${ }^{9}$ Institute for Urology and Reproductive Health, Sechenov University, Moscow, Russia ${ }^{10}$ Department of Urology, King Fahad Specialist Hospital, \\ Dammam, Saudi Arabia ${ }^{11}$ Department of Urology, Jikei University School of Medicine, Tokyo, Japan ${ }^{12}$ Research Center for Evidence Based Medicine, Tabriz University of \\ Medical Sciences, Tabriz, Iran ${ }^{13}$ Fondazione IRCCS Istituto Nazionale dei Tumori, Milan, Italy ${ }^{14}$ Department of Urology, University Hospital of Tours, Tours, France
}

\section{Abstract}

Introduction Medical organizations have provided evidence-based guidelines for penile cancer treatment. This current review aims to compare and appraise guidelines on penile cancer treatment to provide a useful summary for clinicians.

Materials and Methods We searched in PubMed and Medline for guidelines published between January 1, 2010, and February 1, 2020. The search query terms were "penile cancer," "penile tumor," "guidelines," and "penile malignancy." In the final analysis, we include the most recent versions of relevant guidelines published in English. The Appraisal of Guidelines for Research and Evaluation II (AGREE II) instrument was used to appraise the quality of each guideline.

Results In the final analysis, we included guidelines from the National Comprehensive Cancer Network (updated in 2020), The European Association of Urology (updated in 2018), and The European Society for Medical Oncology (published in 2013). The overall agreement among reviewers was excellent. The range of scores for each domain was as follows: scope and purpose (46\% to 61\%); stakeholder involvement (33\% to 60\%); rigor of development (34\% to $69 \%)$; clarity and presentation (61\% to $81 \%$ ); applicability (33\% to $59 \%$ ) and editorial independence (52\% to $78 \%)$. The European Association of Urology and National Comprehensive Cancer Network clinical practice guidelines received better scores according to the AGREE II evaluation.

Conclusion Despite the effort made by the guidelines groups to make a practical guideline regarding penile cancer treatment, the actual available evidence is weak. However, we believe our recommendations offer clear guidance.

\section{Introduction}

Penile cancer is an aggressive disease that represents less than $1 \%$ of all malignancies in the United States and Europe[1,2]. Penile cancer is common in the elderly, with a peak incidence in the seventh decade of life[3]. The most com $\neg$ mon histological subtype for penile cancer is squamous cell carcinoma[4]. Given the complex nature of penile cancer, different therapeutic options are available. Furthermore, there is growing interest in molecularly targeted

\section{Key Words}

Guidelines, penile cancer, penile malignancy, penile tumor

\section{Competing Interests}

None declared
Article Information

Received on December 22, 2020

Accepted on March 1, 2021

Soc Int Urol J.2021;2(3):171-186

DOI: https://doi:10.48083/TKFP8406 


\section{Abbreviations \\ AGREE II Appraisal of Guidelines for Research and Evaluation II NCCN National Comprehensive Cancer Network \\ EAU European Association of Urology \\ ESMO European Society for Medical Oncology \\ EBRT external beam radiation therapy \\ PLND pelvic lymph node dissection \\ LOE level of evidence \\ GOR grade of recommendation}

therapy, and tyrosine kinase inhibitors are showing promising results[5]. However, because of its rarity, most of the recommendations mainly rely on retrospective studies[6,7].

In the last decade, several scientific organizations have provided evidence-based guidelines to improve patients' selection of each treatment modality. The European Association of Urology (EAU) guidelines on Penile Cancer were first published in 2000 and were last updated in 2018. The National Comprehensive Cancer
Network (NCCN) penile cancer guidelines were last updated in 2020, while the last European Society for Medical Oncology (ESMO) clinical practice guidelines was released in 2013.

This study aims to conduct a review, comparison, and appraisal of the guidelines on the treatment of penile cancer to provide universal and practical guidance for physicians in their clinical decision-making. We aimed to provide authoritative guidance with clear recommendations from the best guidelines.

\section{Materials and Methods}

We searched PubMed and Medline for guidelines published between January 1, 2010, and February 1, 2020. The search terms were "penile cancer," "penile tumor," "guidelines," and "penile malignancy." Also, we searched through the websites of international urology and oncology societies for the most recent guidelines on penile cancer. In the final analysis, we included the most recent English version of each guideline. Non-English national guidelines were excluded. The Appraisal of Guidelines for Research and Evaluation

\section{TABLE 1.}

Guidelines for the management penile cancer according to T stage
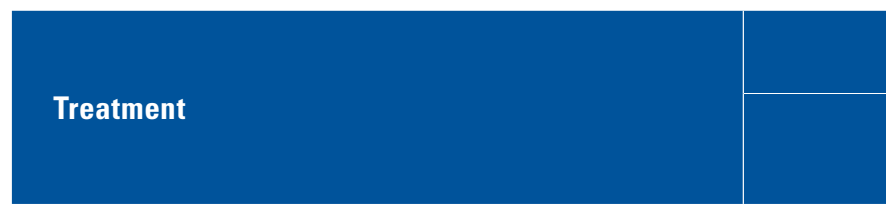

\section{EAU Guidelines}

\section{STAGE Tis}

Topical treatment with 5-fluorouracil (5-FU) or imiquimod

Laser ablation

Glans resurfacing

Wide local excision with circumcision
5-FU is an effective first-line treatment $\quad \begin{gathered}\text { Strong } \\ \text { recommendation }\end{gathered}$

( $\mathrm{Nd}: \mathrm{YAG}$ ) or Carbon dioxide $\left(\mathrm{CO}_{2}\right)$ laser is an effective treatment option

Strong recommendation

Glans resurfacing, total or partial, can be a primary treatment for PeIN or a secondary 
II (AGREE II) instrument was used to appraise the quality of guidelines[8]. This instrument permits the evaluation of the scope and purpose of the guidelines, stakeholder involvement, rigor of development, clarity of presentation, applicability, and editorial independence. The overall assessment is the final mean of all domains, which gives an overview of each guideline score. The AGREE II recommends 2 or more appraisers. Therefore, each guideline was evaluated by 5 appraisers (BP, EL, $\mathrm{FQ}, \mathrm{HM}$, and $\mathrm{KM}$ ) to enhance the authenticity of the assessment. The appraisal was performed after the completion of an online training module on AGREE II website[9]. The 5 reviewers were experienced in urologic oncology and were mentored by 2 oncologic urologists (SFS, BP) experienced in guidelines writing and grade of recommendation rating.

\section{Results}

Guidelines from 3 international organizations were included in the final analysis: the 2020 update of the NCCN guideline[10], the 2018 update of the EAU guidelines[11], and the 2013 update of the ESMO guidelines[12].

\section{Level of evidence assessment and grading of recommendations}

Two guidelines (EAU and NCCN) provided a detailed and strict methodology for searching and acquisition of evidence from the literature. The ESMO guideline is an expert consensus statement so did not include a systematic literature search. All 3 guidelines (EAU, $\mathrm{NCCN}$, and ESMO) provided a description of the systems used for grading the level of evidence. In the EAU guidelines, a modified Grading of Recommendations Assessment, Development, and Evaluation (GRADE) was used $[13,14]$. For each recommendation within the guidelines, there was also an accompanying online strength rating form, which addresses several elements. The NCCN guidelines used the Categories of Evidence and Consensus to grade the recommendations; they also provide Categories of Preference to help users chose the optimal recommendation based on efficacy, safety, evidence, or affordability.

The ESMO guidelines adapted the Infectious Diseases Society of America-United States Public Health Service Grading System [15].
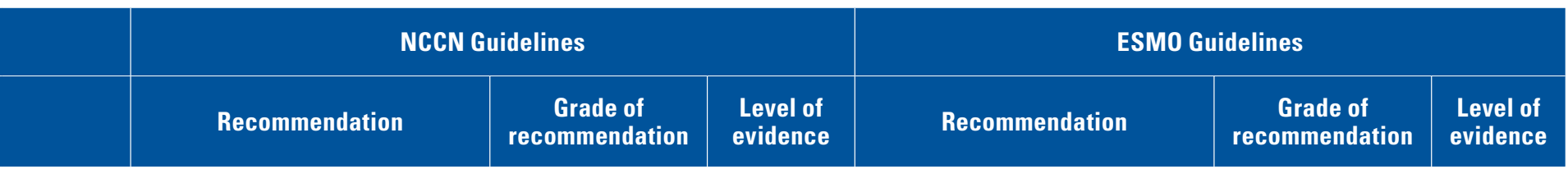

\begin{tabular}{c|c} 
Tis, Ta, and T1 penile cancer & \\
lesions may be amenable to & Considered \\
conservative penile organ-sparing & appropriate \\
approaches, including topical & \\
therapy & \\
\hline
\end{tabular}

The use of therapeutic lasers to treat selected primary penile tumors has been reported with acceptable outcomes
Glansectomy, removal of the glans penis, may be considered for patients with distal tumors

Penile tumors of the shaft may be treated with wide local excision, with or without circumcision \begin{tabular}{c|c|c}
$\begin{array}{c}\text { Considered } \\
\text { appropriate }\end{array}$ & 2B & Laser therapy using CO2 or \\
Nd: YAG laser
\end{tabular}

Considered appropriate

Considered appropriate
2A
2B Partial/total glans resurfacing

Wide local excision and circumcision
$2 A$

Penile-preserving techniques,
including topical therapy
(5\% 5-fluorouracil and

$5 \%$ imiquimod cream) C IV
III
C

C

III
C IV 


\section{TABLE 1.}

Guidelines for the management penile cancer according to T stage, Cont'd
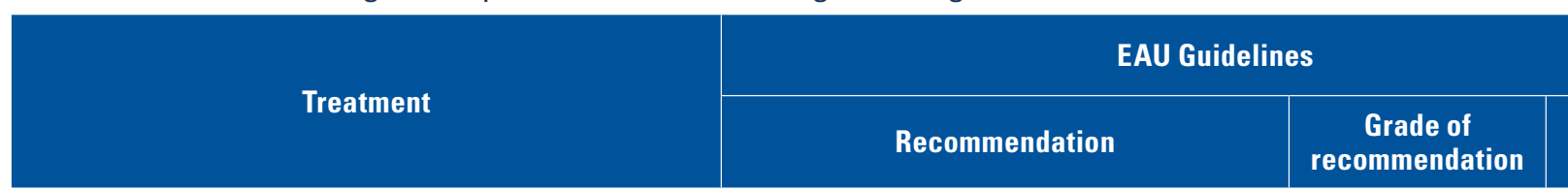

Level of

Recommendation

recommendation

evidence

STAGE Ta, T1a (G1, G2)

Wide local excision with circumcision

Glans resurfacing

Glansectomy with reconstruction

Radiotherapy
Partial glansectomy or total glansectomy with reconstruction are surgical options

Partial glansectomy or total glansectomy with reconstruction are surgical options

Partial glansectomy or total glansectomy with reconstruction are surgical options

External beam radiotherapy or brachytherapy is radiotherapeutic options
Strong

recommendation

Strong

recommendation

Strong

recommendation

Strong
recommendation

2B

Strong

recommendation

Strong

recommendation

Small lesions can also be

treated by laser therapy

Strong

recommendation

\section{STAGE T1B (G3) AND T2}

Wide local excision plus reconstruction

Glansectomy with circumcision
and reconstruction

Radiotherapy

Total penectomy OR Partial
Local excision, partial glansectomy or total glansectomy with reconstruction are surgical options

Local excision, partial glansectomy or total glansectomy with reconstruction are surgical options

External beam radiotherapy or brachytherapy

is radiotherapeutic options

Total glansectomy, with or without resurfacing of the corporeal heads, is recommended
Strong

recommendation

Strong

recommendation

Strong

recommendation

Strong

recommendation 
NCCN Guidelines

Recommendation

Grade of

recommendation

Considered

appropriate

treated wis of the shaft may be

with or without circumcision

Glansectomy may be considered

for select patients with distal

tumors
Considered

appropriate
ESMO Guidelines

Level of

evidence

\begin{tabular}{|l|c|c|}
\hline \multicolumn{3}{|c|}{ ESMO Guidelines } \\
\hline Recommendation & $\begin{array}{c}\text { Grade of } \\
\text { recommendation }\end{array}$ & $\begin{array}{c}\text { Level of } \\
\text { evidence }\end{array}$ \\
\hline
\end{tabular}

Penile-preserving techniques, including wide local excision plus

reconstructive surgery

III

2B
C

Glansectomy is not recommended unless required to ensure complete tumor eradication with negative margins

Considered appropriate

Considered appropriate
Radiotherapy delivered as EBRT or brachytherapy with interstitial implant
C

IV
2B
2A

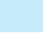

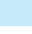

The use of therapeutic lasers to treat selected primary penile tumors has been reported with acceptable outcomes

Partial or total penectomy

Considered appropriate

2B Laser therapy

C IV when invasion into the corpora cavernosum is necessary to achieve a negative margin

Considered appropriate

Mohs surgery is an alternative to wide local excision in select cases.
Considered appropriate
2B
Penile tumors of the shaft may be treated with wide local excision

Glansectomy may be considered for select patients with distal tumors

Consider $<4 \mathrm{~cm}$ : Brachytherapy or EBRT $>4 \mathrm{~cm}$ : EBRT with chemotherapy

Partial or total penectomy when invasion into the corpora cavernosum is necessary to achieve a negative margin
Considered appropriate

Considered appropriate

Considered appropriate

Considered appropriate
2A

Tumors with invasion into corpora cavernosa
If tumor $<50 \%$ of the glans and no invasion of the corpora cavernosa

If tumor $<50 \%$ of the glans and no invasion of the corpora cavernosa

$<4 \mathrm{~cm}$ : Brachytherapy or EBRT

2B $>4 \mathrm{~cm}$ : EBRT with chemotherapy III

B

III

B

III

III 
TABLE 1.

Guidelines for the management penile cancer according to T stage, Cont'd

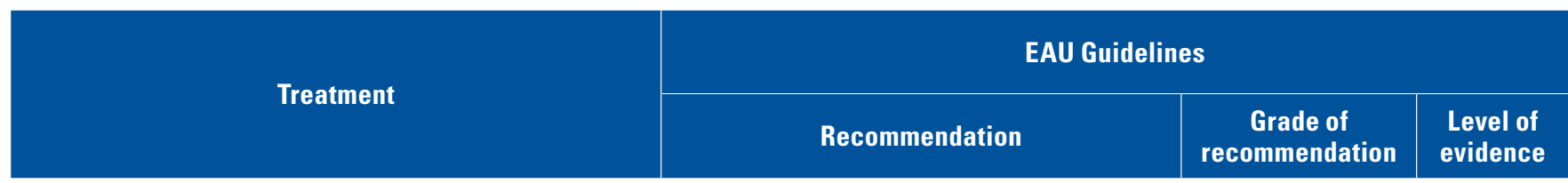

STAGE T2

Total glansectomy

Radiotherapy

Total penectomy OR Partial
Total glansectomy, with or without resurfacing of the corporeal heads, is recommended

Radiation therapy is an option
Strong
recommendation 3
Partial amputation should be considered in patients unfit for reconstructive surgery
Strong recommendation

\section{STAGE T3}

Partial amputation with reconstruction or total penectomy

Radiotherapy
Glansectomy with distal corporectomy and reconstruction or partial amputation with reconstruction are standard

Strong

recommendation
Strong

recommendation

\section{STAGE T3 WITH INVASION OF THE URETHRA}

Partial penectomy or total penectomy

Radiotherapy
Glansectomy with distal corporectomy and reconstruction or partial amputation with reconstruction are standard

Radiation therapy is an option
Strong

recommendation

Strong

recommendation

\section{STAGE T4}

\section{Partial penectomy or total penectomy}

Radiotherapy
Extensive partial amputation or total penectomy with perineal urethrostomy is the standard advisable treatment
Weak

recommendation 
NCCN Guidelines

\section{Recommendation}

\begin{tabular}{|c|c|c|c|} 
Grade of \\
recommendation
\end{tabular}

\section{ESMO Guidelines}

Level of evidence
Grade of Recommendation

\section{Consider}

$<4 \mathrm{~cm}$ : Brachytherapy or EBRT

$>4 \mathrm{~cm}$ : EBRT with chemotherapy

Partial or total penectomy when invasion into the corpora cavernosum is necessary to achieve a negative margin
III
Partial or total penectomy when invasion into the corpora cavernosum is necessary to achieve a negative margin

EBRT with chemotherapy are treatment options
Considered appropriate

Considered appropriate
2B

$<4 \mathrm{~cm}$ : Brachytherapy or EBRT

$>4 \mathrm{~cm}$ : EBRT with chemotherapy

2A

Tumors with invasion into corpora cavernosa
Considered
appropriate
2A
T3-4 or N+: circumcision followed by EBRT with chemotherapy

B

D

Considered appropriate

3
D
Partial or total penectomy when invasion into the corpora cavernosum is necessary to achieve a negative margin

EBRT with chemotherapy are treatment options
Considered
appropriate
2A
T3-4 or N+: circumcision followed by EBRT with chemotherapy

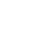


TABLE 2.

Author recommendations for penile cancer guidelines

\begin{tabular}{|c|c|c|c|c|}
\hline & Topical & Laser & Surgery & Radiotherapy \\
\hline $\begin{array}{l}\text { Ta, T1 \& T2 } \\
\text { confined to } \\
\text { the glans }\end{array}$ & $x$ & $\begin{array}{l}\text { Tis } \rightarrow \text { T2 } \text { glans } \\
\text { Laser ablation } \\
\text { with CO2 or } \\
\text { Nd:YAG laser }\end{array}$ & $\begin{array}{l}\text { - Glans resurfacing (Removal } \\
\text { of glans epithelium) for lesions } \\
\text { confined to glans } \\
\text { - Glansectomy (Leaving corpora } \\
\text { intact } \\
\text { compared to partial penectomy) } \\
\text { - Circumcision for lesions } \\
\text { confined } \\
\text { to prepuce } \\
\text { - Wide local excision } \\
\text { + reconstruction } \pm \text { skin grafting }\end{array}$ & $\begin{array}{l}\text { Ta } \rightarrow \text { T2 } \\
\text { Radiotherapy by } \\
\text { - External beam } \\
\text { - (EBRT) or as } \\
\text { - Brachytherapy }\end{array}$ \\
\hline $\begin{array}{l}\text { T3 (Three) } \\
\text { invasion of } \\
\rightarrow \text { Urethra }\end{array}$ & $x$ & $x$ & $\begin{array}{l}\text { - Partial penectomy } \\
\text { - Total penectomy with perineal } \\
\text { urethrostomy }\end{array}$ & \\
\hline $\begin{array}{l}\text { T4 } \rightarrow \text { Adjacent } \\
\text { structures }\end{array}$ & $X$ & $X$ & $\begin{array}{l}\text { - Neoadjuvant chemo + surgery } \\
\text { in responders }\end{array}$ & or Palliative EBRT \\
\hline
\end{tabular}

\section{Nodal metastases}

No palpable inguinal nodes $>$ T1G2

Tis, Ta G1, T1G1

\begin{tabular}{|c|c|c|c|c|}
\hline $\begin{array}{l}\text { confined to } \\
\text { the glans }\end{array}$ & $x$ & & $\begin{array}{l}\text { to prepuce } \\
\text { - Wide local excision } \\
\text { + reconstruction } \pm \text { skin grafting }\end{array}$ & $\begin{array}{l}\text { - External beam } \\
\text { - (EBRT) or as } \\
\text { - Brachytherapy }\end{array}$ \\
\hline $\begin{array}{l}\text { T2 } \rightarrow \text { Corpora } \\
\text { cavernosa (CC) }\end{array}$ & $x$ & $x$ & $\begin{array}{l}\text { Partial penectomy + } \\
\text { reconstruction }\end{array}$ & \\
\hline $\begin{array}{l}\text { T3 (Three) } \\
\text { invasion of } \\
\rightarrow \text { Urethra }\end{array}$ & $x$ & $x$ & $\begin{array}{l}\text { - Partial penectomy } \\
\text { - Total penectomy with perineal } \\
\text { urethrostomy }\end{array}$ & \\
\hline $\begin{array}{l}\text { T4 } \rightarrow \text { Adjacent } \\
\text { structures }\end{array}$ & $x$ & $x$ & $\begin{array}{l}\text { - Neoadjuvant chemo + surgery } \\
\text { in responders }\end{array}$ & or Palliative EBRT \\
\hline \multicolumn{5}{|c|}{ Nodal metastases } \\
\hline \multicolumn{2}{|c|}{ No palpable inguinal nodes } & Palpable (cN1/cN2) & Fixed (cN3) & Pelvic lymphadenopathy \\
\hline $\begin{array}{l}\text { Tis, Ta G1, } \\
\text { T1G1 }\end{array}$ & $>\mathrm{T} 1 \mathrm{G} 2$ & \multirow[b]{2}{*}{$\begin{array}{l}\text { Radical inguinal } \\
\text { lymphadenectomy }\end{array}$} & \multirow{2}{*}{$\begin{array}{l}\text { Neoadjuvant chemotherapy } \\
\pm \text { followed in responders by } \\
\text { Radical inguinal } \\
\text { lymphadenectomy }\end{array}$} & \multirow{2}{*}{$\begin{array}{l}\text { Ipsilateral pelvic } \\
\text { lymphadenectomy if } \\
\text { (pN2) } \geq \mathbf{2} \text { inguinal nodes are } \\
\text { involved on one side and if } \\
\text { (pN3) Extracapsular nodal } \\
\text { metastasis }\end{array}$} \\
\hline Surveillance & $\begin{array}{l}\text { Staging by } \\
\text { Dynamic } \\
\text { sentinel node } \\
\text { biopsy }\end{array}$ & & & \\
\hline
\end{tabular}

Palpable (cN1/cN2)

Fixed (cN3)
Pelvic lymphadenopathy

Chemotherapy

- Neoadj.: T4, fixed N3

- Adjuvant: pN2/pN3
Adjuvant chemo in $\mathbf{p N 2 / p N 3}$ patients after radical lymphadenectomy 3-4 cycles of TPF: paclitaxel, cisplatin, 5-fluorouracil (5FU)

\section{Treatment strategy according to stage}

\section{Organ-sparing treatment in $\mathrm{Tis}, \mathrm{Ta}$, and $\mathrm{T} 1 \mathrm{a}$ tumors}

All 3 guidelines (EAU, NCCN, and ESMO), advise organ-sparing approaches in patients diagnosed with $\mathrm{Tis}, \mathrm{Ta}$, and $\mathrm{T} 1$ penile cancer lesions. However, the EAU guidelines highlight the absence of randomized controlled trials or comparative observational studies for treatment options for localized penile
Ipsilateral pelvic lymphadenectomy if (pN2) $\geq \mathbf{2}$ inguinal nodes are involved on one side and if (pN3) Extracapsular nodal metastasis \pm followed in responders by

Radical inguinal

Iymphadenectomy 
Before their use, the EAU guidelines recommend performing a circumcision. The EAU and NCCN guidelines make clear that there is a requirement for long-term surveillance. Another option is laser therapy, which could be performed as day-case surgery. When laser therapy is performed, the EAU guidelines mandate a second biopsy before treatment is initiated. A partial or total glans resurfacing can be an alternative in the firstline treatment for penile intraepithelial lesions (PeIN) or could be proposed after topical or laser therapy failure. In the case of wide local excision, Mohs surgery can be proposed in selected cases according to the EAU and NCCN guidelines (Table 1).

Summary of treatment recommendations: For patients with penile Tis or Ta, we recommend topical therapy $[17,18]$ and excisional organ-sparing technique[19], a topical agent such as imiquimod (5\%) or 5-fluorouracil (5FU) cream, circumcision and wide local excision, laser therapy, or complete glansectomy (Table 2).

\section{Invasive disease treatment confined to the glans $\mathrm{T} 1 / \mathrm{T} 2$}

For T1 and T2 tumors localized to the glans, the 3 guidelines proposed different strategies, including surgery with laser therapy, local excision, partial glansectomy, or total glansectomy, and radiotherapy or brachytherapy. For the treatment of invasive disease confined to the glans, the EAU and the ESMO guidelines agree on conservative approaches, such as wide local excision or glansectomy, while the NCCN guidelines recommended it only in T1 high grade (G3-4).

For radiotherapy, the NCCN and the EAU guidelines recommended brachytherapy or external beam radiation therapy (EBRT) for tumors less than $4 \mathrm{~cm}$. A circumcision is mandated by the NCCN guidelines before radiotherapy (RT) to prevent radiationrelated complications. For tumors larger than $4 \mathrm{~cm}$, a multimodal treatment combining radiotherapy and chemotherapy is recommended (Table 1).

Summary of treatment recommendations: Our recommendation for the treatment of invasive disease confined to the glans is a glansectomy with or without resurfacing with a partial thickness skin graft of the corporeal heads[20]. A partial amputation for patients who are not candidates for reconstructive surgery should be performed[21]. Radiotherapy may also be an option[22] (Table 2).

\section{Treatment of invasive disease T3/T4}

For tumors with invasion of the corpora cavernosum, a partial or total penectomy is mandatory to achieve a total resection with negative margin according to the $\mathrm{NCCN}$ and the EAU guidelines. EBRT with concurrent chemotherapy is also an option in the NCCN guidelines, while it is the primary treatment in the ESMO guidelines. The EAU guidelines consider radiation as a treatment option only for T3 and as a palliative treatment in T4 disease (Table 1).

Summary of treatment recommendations: For the treatment of cT3, we recommend glansectomy with corporectomy and reconstruction or partial penectomy with reconstruction as a standard of care $[23,24]$. Total penectomy with perineal urethrostomy is considered in selected cases. For cT4 disease, the recommended treatment remains a total penectomy with perineal urethrostomy[24]. Neoadjuvant chemotherapy for the locally advanced disease should be systematically considered and proposed[25,26] (Table 2).

\section{Guidelines for treatment strategies for nodal metastases: cNO}

The ESMO, NCCN, and EAU guidelines all recommend surveillance for Tis, Ta G1, and T1G1 stages. Invasive lymph node staging either by bilateral modified inguinal lymphadenectomy or by dynamic sentinel node biopsy is recommended for $\geq \mathrm{T} 1 \mathrm{G} 2$ (Table 3 ). There is currently no role for prophylactic radiation to the inguinal lymph nodes instead of lymph node dissection or biopsy[27].

Summary of treatment recommendations: There are considerable discussions among researchers in the management of cN0 disease. Nonetheless, we believe that it is justified to recommend surveillance for Tis, Ta G1, and T1G1 if the patient is compliant[28]. In contrast, at least a dynamic sentinel node biopsy should be recommended to improve the outcome for $\geq$ T1G2 disease[29] (Table 2).

\section{Guidelines for treatment strategies for nodal metastases: cN1/cN2}

All 3 guidelines recommend a radical inguinal lymphadenectomy for clinically positive lymph nodes. The confirmation of clinically positive lymph nodes should be made by surgical resection and frozen section according to the EAU guidelines, while, according to the NCCN, the confirmation can be made by percutaneous biopsy, or by fine-needle aspiration (FNA) in the ESMO guidelines (Table 3).

Summary of treatment recommendations: Radical inguinal lymphadenectomy seems to improve survival and should be recommended for every patient with cN1/N2[30] (Table 2).

Guidelines for treatment strategies for nodal metastases: cN3

For fixed inguinal nodal mass or pelvic lymphadenopathy (cN3), neoadjuvant chemotherapy 
TABLE 3.

Guidelines for the management of nodal metastasis and adjuvant therapy for penile cancer

\begin{tabular}{|l|c|c|c|c|c|}
\hline \multicolumn{3}{|c|}{ EAU Guidelines } & \multicolumn{3}{c|}{ NCCN Guidelines } \\
\hline Recommendation & $\begin{array}{c}\text { Grade of } \\
\text { recommendation }\end{array}$ & $\begin{array}{c}\text { Level of } \\
\text { evidence }\end{array}$ & Recommendation & $\begin{array}{c}\text { Grade of } \\
\text { recommendation }\end{array}$ & $\begin{array}{c}\text { Level of } \\
\text { evidence }\end{array}$ \\
\hline
\end{tabular}

\section{STAGE CNO}

Surveillance is only recommended in patients with $\mathrm{pTis} / \mathrm{pTa}$ tumors

\author{
Strong \\ recommendation
}

Most low-risk patients are

followed with a surveillance

as the probability of occult micro

metastases in ILNs is low
Considered

appropriate

2A
> T1G2: invasive lymph node staging is recommended by either bilateral modified inguinal lymphadenectomy or dynamic sentinel node biopsy

\begin{tabular}{c|c|c|c}
$\begin{array}{c}\text { Strong } \\
\text { recommendation }\end{array}$ & 2B & $\begin{array}{c}\text { For high-risk standard or modified } \\
\text { ILND or DSNB is strongly } \\
\text { recommended in high-risk }\end{array}$ & $\begin{array}{c}\text { Considered } \\
\text { appropriate }\end{array}$ \\
\hline
\end{tabular}

Considered

$2 A$

Percutaneous lymph node biopsy

is considered standard

Positive findings warrant an

immediate ILND
Strong
recommendation

2B
2A
Should receive neoadjuvant Chemotherapy followed by radical inguinal and PLND lymphadenectomy in responders
Considered appropriate

\section{A radical inguinal
lymphadenectomy should be performed \\ STAGE CN3 \\ Multimodal treatment with neoadjuvant chemotherapy \\ followed by radical lymphadenectomy in responders is recommended \\ STAGE CN1/CN2}

recommendation 


\section{ESMO Guidelines}

Recommendation

Grade of

recommendation

Level of

evidence
Low- risk (Tis, Ta, T1G1) and intermediate-risk (T1G2) are followed with surveillance

DSNB is recommended in patients with non-palpable inguinal lymph nodes T1G2 or greater
B

B

Fine-needle aspiration (FNA) of the $L N$ is standard for these patients (omitting the procedure for high-risk tumors to avoid delay of (LND)

Patients with fixed nodes should be considered for neoadjuvant chemoradiotherapy

Responders receive consolidation surgery (bilateral and deep ILND and ipsilateral PLND if possible)
Patients with fixed nodes should be considered for neoadjuvant chemoradiotherapy

Responders receive consolidation surgery (bilateral and deep ILND and ipsilateral PLND if possible) followed by a radical lymphadenectomy is supported by both NCCN and EAU guidelines. The ESMO guidelines recommend a multimodal treatment including chemoradiotherapy followed by consolidation surgery (inguinal lymph node dissection [ILND] and ipsilateral pelvic lymph node dissection [PLND]). This treatment regimen is one of the options in the NCCN guidelines but is considered only as a palliative treatment in the EAU guidelines (Table 3).

Summary of treatment recommendations: For $\mathrm{cN} 3$, we recommend a radical lymphadenectomy after neoadjuvant chemotherapy for every responder to improve disease-free survival[25] (Table 2).

\section{Enlarged pelvic lymph nodes}

For surgically resectable lesions, all 3 guidelines recommend neoadjuvant systemic chemotherapy, followed by unilateral/bilateral PLND in case of treatment response. The EAU guidelines recommend lymphadenectomy for ipsilateral PLND if 2 or more inguinal lymph nodes are affected on one side or if extracapsular nodal metastasis is reported, followed by adjuvant chemotherapy. For enlarged pelvic lymph nodes where surgery is not possible, the NCCN and the ESMO guidelines recommend chemo-radiotherapy (Table 3).

Summary of treatment recommendations: PLND is recommended for patients with 2 or more inguinal lymph nodes affected on one side or if extra-nodal extension is found[31] (Table 2).

\section{Guidelines for chemotherapy}

Both the EAU and ESMO guidelines state that neoadjuvant chemotherapy followed by radical surgery is advisable in unresectable lymph node metastases. The NCCN guidelines recommend neoadjuvant chemotherapy in patients with $\geq 4 \mathrm{~cm}$ inguinal lymph nodes (fixed or mobile). The EAU and ESMO guidelines recommend adjuvant chemotherapy after lymphadenectomy in patients with $\mathrm{pN} 2 / \mathrm{pN} 3$ disease. In contrast, the NCCN guidelines recommended adjuvant chemotherapy only if it was not given preoperatively, and if the pathology shows high-risk features (Tables 3,4).

Summary of treatment recommendations: A neoadjuvant chemotherapy should be proposed systematically for patients with $\mathrm{cN} 3$ inguinal lymph nodes and discussed for all clinical lymph nodes $\geq$ $4 \mathrm{~cm}$. An adjuvant chemotherapy should be offered to patients with $\mathrm{pN} 2 / \mathrm{pN} 3$ disease without previous systemic treatment. Three to 4 cycles of paclitaxel, cisplatin, 5-fluorouracil (5FU) are the recommended regimen[32-34] (Table 2). 
TABLE 3.

Guidelines for the management of nodal metastasis and adjuvant therapy for penile cancer, Cont'd

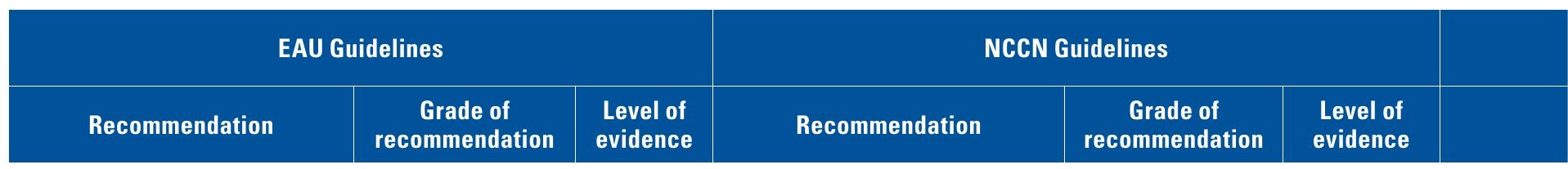

\section{STAGE CHEMOTHERAPY}

Neoadjuvant chemotherapy using cisplatin- and the taxanebased triple combination should be used in patients with fixed, unresectable, nodal disease
Neoadjuvant chemotherapy with TIP (paclitaxel, ifosfamide, and cisplatin) is preferred

Strong recommendation (prior to ILND) in patients with $\geq 4 \mathrm{~cm}$ inguinal lymphnodes (fixed or mobile)

Adjuvant chemotherapy it is reasonable to give four courses

2B

$2 A$ of TIP in the adjuvant setting if it was not given preoperatively and the pathology shows high-risk features

\section{STAGE RADIOTHERAPY}

Not recommended for nodal disease except as a palliative option

Strong
recommendation

Adjuvant EBRT or chemoradiotherapy can also be considered for patients with high-risk features
Considered appropriate

2A

TABLE 4.

Guidelines of chemotherapy regimen for penile cancer

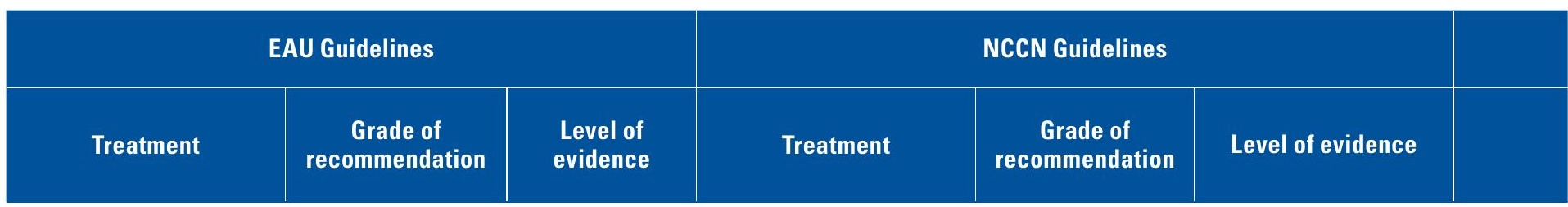

\section{NEOADJUVANT CHEMOTHERAPY}

\begin{tabular}{c|c|c|c|c|c|}
\hline $\begin{array}{c}\text { (4 cycles) } \\
\text { cisplatin- and taxane- } \\
\text { based regimen }\end{array}$ & Weak & 2A & (4 courses) & $\begin{array}{c}\text { Considered } \\
\text { appropriate }\end{array}$ \\
\hline
\end{tabular}

\section{ADJUVANT CHEMOTHERAPY}

\section{(3 to 4 cycles)}

cisplatin, a taxane and 5-fluorouracil or ifosfamide
(4 courses)

Preferred regimen is TIP (paclitaxel, ifosfamide, and cisplatin)

2A

Considered appropriate

2B

Other recommended regimen is 5 - fluorouracil + cisplatin 


\section{ESMO Guidelines}

Recommendation
Level of evidence
Neoadjuvant chemotherapy followed by radical surgery is advisable in unresectable or

C recurrent LN metastases

Adjuvant chemotherapy is recommended in pN2-3 patients

The role of adjuvant postoperative radiation is controversial

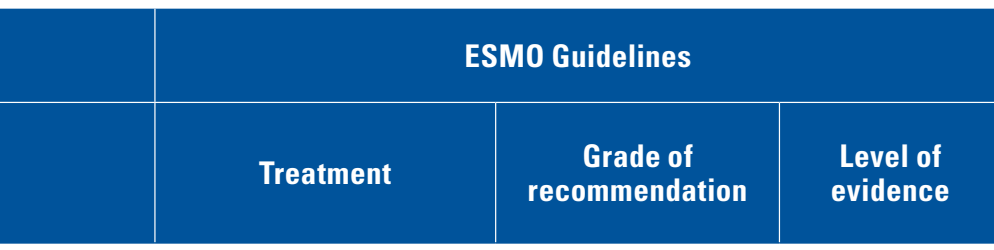

(4 courses)

TIP (paclitaxel, ifosfamide,

C
C

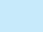

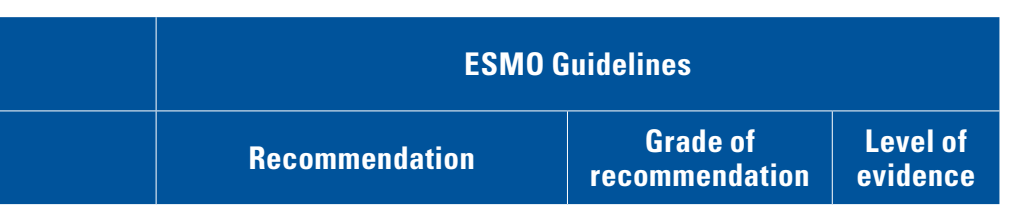

and cisplatin)

No clear recommendation

\section{Guidelines for Adjuvant Radiotherapy}

NCCN guidelines indicate that adjuvant EBRT or chemo-radiotherapy can be considered for patients with high-risk features, but the EAU guidelines do not recommend it except for palliative treatment. According to the ESMO guidelines, the role of adjuvant radiotherapy in the management of penile cancer remains controversial (Tables 3,4).

Summary of treatment recommendations: Adjuvant radiotherapy is recommended after PLND for patients with positive results in $\operatorname{ILND}[35,36]$.

\section{Assessment of the quality of the guidelines with the AGREE II instrument}

The AGREE Instrument is a 23-item tool comprising 6 quality and 2 overall assessment domains. A unique dimension of guideline quality is captured in each domain. Table 3 shows the results of the guidelines appraisal by the 5 reviewers. For the Domain 1 scope and purpose, which is related to the specific health questions, the overall aim of the guideline, and the target population, EAU and NCCN both scored $61 \%$, while ESMO scored only $46 \%$. Concerning the stakeholder involvement focuses on the extent to which the guidelines were developed by the appropriate stakeholders, the lowest score was 33\% for ESMO, while EAU and NCCN reached approximately the same score with $59 \%$ and $60 \%$, respectively. Regarding rigor of development concerned with the approaches to formulate the recommendations and the process used to gather and make the evidence and to update them, the appraiser gave the best score to the EAU and NCCN guidelines with $69 \%$ and $61 \%$, respectively; while the ESMO, with a score of $34 \%$ did not reach the expected standard. With respect to structure, language, format, and clarity of presentation, the NCCN had a score of $81 \%$, followed by the EAU, with $77 \%$, and the ESMO with $61 \%$. Resource implications of applying the guideline, strategies to improve uptake, and applicability pertaining to the likely barriers to and facilitators of implementation were scored at 33\%,53\%, and 59\% for the ESMO, NCCN, and EAU guidelines, respectively. For editorial independence, which concerns there being no competing interests that might bias the formulation of recommendations, the scores were $78 \%$ for the EAU guidelines, $57 \%$ for the ESMO guidelines, and 52\% for the NCCN guidelines. Overall assessment includes rating the recommendation of guidelines for practice use and the overall quality of the guidelines. The highest score was reached by the EAU guidelines with a total rate of $77 \%$, and the lowest score by the ESMO guidelines with a rate of $40 \%$, while the NCCN guidelines also reached a high rate with $73 \%$ (Table 5). 
TABLE 5.

AGREE II evaluation of guidelines for the management of penile cancer

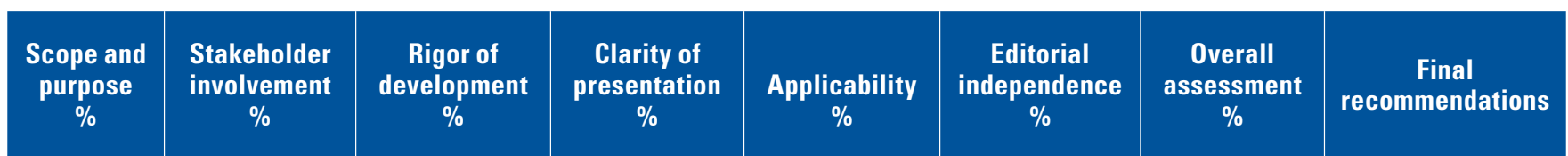

EAU GUIDELINES

\begin{tabular}{|c|c|c|c|c|c|c|c|}
\hline 61 & 59 & 6 & 77 & 59 & 78 & 77 & $\begin{array}{l}\text { Yes-3, Yes with } \\
\text { modifications-2, } \\
\text { No-0 }\end{array}$ \\
\hline \multicolumn{8}{|c|}{ NCCN GUIDELINES } \\
\hline 6 & 60 & 61 & 81 & 53 & 52 & 73 & $\begin{array}{c}\text { Yes-3, Yes with } \\
\text { modifications-2, } \\
\text { No-0 }\end{array}$ \\
\hline \multicolumn{8}{|c|}{ ESMO GUIDELINES } \\
\hline 46 & 33 & 34 & 61 & 33 & 57 & 40 & $\begin{array}{l}\text { Yes- } 0 \text {, Yes with } \\
\text { modifications-2, } \\
\text { No-3 }\end{array}$ \\
\hline
\end{tabular}

\section{Discussion}

Clinical guidelines help physicians to choose the best treatment available for individual patients. Fewer guidelines are available in the case of rare diseases, and only 3 guidelines in English have been published on the management of penile cancer. The recommendations made in these guidelines are not always in agreement. Therefore, to help urologists in their decision-making process regarding therapy, we evaluated and compared the guidelines of the NCCN, EAU, and ESMO on the management of penile cancer. Using the AGREE II tool, we assessed the quality of the guidelines. We discuss the differences in terms of LOE and GOR that arise as a result of different methods of evaluation used. The EAU and NCCN guidelines incorporate more recent literature than the ESMO guidelines, which have not been updated for 7 years.

The EAU guidelines use a modified Grading of Recommendations Assessment, Development, and Evaluation (GRADE) methodology. For each recommendation within the guidelines, there is an accompanying online strength rating form that addresses several elements. The ESMO adapted the Infectious Diseases Society of America-United States Public Health Service Grading System. The level of evidence assessment and grading of recommendations in NCCN guidelines are based on randomized controlled trials, clinical trials, guidelines, systematic reviews, meta-analysis, and validation studies. Evaluation of LOE and GOR are more specified clearly in the NCCN guidelines than in the other 2 guidelines. Although these 3 guidelines developed in different ways, it is reassuring that they have considerable similarities, albeit some small but potentially significant differences between them. The evidence available is weak in penile cancer, and a consequence of the scarcity in evidence is that way, some recommendations are based on the panel's review of the low-level evidence and expert opinion.

One of the contentious points is the advantage of both neoadjuvant and adjuvant radiotherapy in the treatment of penile cancer patients with LN metastases. There is some evidence for adjuvant nodal radiotherapy in in vulvar carcinoma, which shares many characteristics with penile cancer[37,38]. However, high-quality evidence to suggest a clear benefit to radiotherapy in penile cancer is lacking $[39,40]$. In a retrospective study of 2458 patients in the SEER database (National Cancer Institute Surveillance, Epidemiology and End Results Program), no advantage was observed with the use of EBRT for penile cancer patients compared to surgery alone on cancer-specific survival[41]. A similar conclusion was reached by Franks et al., who reported poor long-term survival for patients treated with adjuvant radiotherapy[42]. These essential findings are consistent with those of other studies, which showed no patient benefit $[43,44-48]$. However, A series of recent studies have indicated that adjuvant radiotherapy improved survival and decreased recurrence rate $[35,36,49]$. 


\section{Conclusion}

This is the first attempt to review and appraise guidelines for penile cancer management systematically. Although all guidelines strive to be evidence-based, some recommendations differ between the guidelines because the underlying evidence is poor. Also, these guidelines are produced in the United States and Europe,

\section{References}

1. Siegel RL, Miller KD, Jemal A. Cancer statistics, 2020. CA Cancer J Clin.2020;70(1):7-30.

2. Bray F, Ferlay J, Soerjomataram I, Siegel RL, Torre LA, Jemal A. Global cancer statistics 2018: GLOBOCAN estimates of incidence and mortality worldwide for 36 cancers in 185 countries. CA Cancer J Clin.2018;68(6):394-424.

3. Bleeker MC, Heideman DAM, Snijders PJF, Horenblas S, Dillner J, Meijeret CLM. Penile cancer: epidemiology, pathogenesis and prevention. World J Urol.2009;27(2):141-150. doi: 10.1007/s00345008-0302-z. Epub 2008 Jul 8.

4. Chipollini J, Tang DH, Sharma P, Spiess PE. National trends and predictors of organ-sparing for invasive penile tumors: expanding the therapeutic window. Clin Genitourin Cancer.2018;16(2):e383-e389. doi: 10.1016/j.clgc.2017.09.004. Epub 2017 Sep 8.

5. Resch I, Abufaraj M, Hübner NA, Shariat SF. An update on systemic therapy for penile cancer. Curr Opin Urol.2020;30(2):229-233. doi: 10.1097/MOU.0000000000000733.

6. Adashek JJ, Necchi A, Spiess PE. Updates in the molecular epidemiology and systemic approaches to penile cancer. Urol Oncol.2019;37(7):403-408.

7. Necchi A. Systemic Therapy for penile cancer. Eur Urol Suppl.2018;17(6):160-163.

8. Brouwers MC, Kho ME, Browman GP, Burgers JS, Cluzeau F, Feder G, et al.; AGREE Next Steps Consortium. AGREE Il: advancing guideline development, reporting and evaluation in health care. CMAJ.2010;182(18):E839-842. doi: 10.1503/cmaj.090449. Epub $2010 \mathrm{Jul} 5$.

9. Practice, A.A.t.S.o. and Guidelines. AGREE website. Available from: https://www.agreetrust.org/. Accessed March 262021.

10. National Comprehensive Cancer Network. Penile Cancer (Version 1.2020). 2020; Available from: https://www.nccn.org/professionals/ physician_gls/pdf/penile.pdf. Accessed March 262021.

11. Hakenberg OW, Compérat E, Minhas S, Necchi A, Protzel C, Watkin N, Robinson R. EAU Guidelines on Penile Cancer 2018, in European Association of Urology Guidelines. 2018 Edition. 2018, European Association of Urology Guidelines Office: Arnhem, The Netherlands. Available from: https://uroweb.org/guideline/penile-cancer/. Accessed March 26, 2021.

12. Van Poppel H, Watkin NA, Osanto S, Moonen L, Horwich A, Kataja V; ESMO Guidelines Working Group. Penile cancer: ESMO clinical practice guidelines for diagnosis, treatment and follow-up. Ann Oncol.2013;24(Suppl) 6:vi115-124. doi: 10.1093/annonc/mdt286. so that their applicability in other regions with a high incidence of penile cancer is uncertain. This point may encourage organizations in other areas to produce their own guidelines. The best way to improve the guidelines is to conduct more prospective trials to strengthen the data underlying the recommendations.

13. Guyatt GH, Oxman AD, Vist GE, Kunz R, Falck-Ytter Y, Alonso-Coello $P$, Schünemann $\mathrm{HJ}$; for the GRADE Working Group. GRADE: an emerging consensus on rating quality of evidence and strength of recommendations. BMJ.2008;336(7650):924-926. 336 doi: https:// doi.org/10.1136/bmj.39489.470347.AD

14. Guyatt GH, Oxman AD, Kunz R, Vist GE, Falck-Ytter Y, Schünemann HJ; GRADE Working Group. What is "quality of evidence" and why is it important to clinicians? BMJ.2008; 336(7651):995-998. doi: 10.1136/bmj.39490.551019.BE.

15. Dykewicz CA, Centers for Disease Control and Prevention (U.S.); Infectious Diseases Society of America; American Society of Blood and Marrow Transplantation. Summary of the guidelines for preventing opportunistic infections among hematopoietic stem cell transplant recipients. Clin Infect Dis.2001;33(2):139-144. doi: 10.1086/321805. Epub 2001 Jun 14.

16. Raskin Y, Vanthoor J, Milenkovic U, Muneer A, Albersen M. Organsparing surgical and nonsurgical modalities in primary penile cancer treatment. Curr Opin Urol.2019 Mar;29(2):156-164. doi: 10.1097/ MOU.0000000000000587.

17. Choi JW, Choi M, Cho KH. A case of erythroplasia of queyrat treated with imiquimod $5 \%$ cream and excision. Ann Dermatol.2009;21(4):419-422.

18. Schroeder TL, Sengelmann RD. Squamous cell carcinoma in situ of the penis successfully treated with imiquimod $5 \%$ cream. J Am Acad Dermatol.2002;46(4):545-548.

19. Feldman AS, McDougal WS. Long-term outcome of excisional organ sparing surgery for carcinoma of the penis. J Urol.2011;186(4):1303-1307.

20. Azrif M, Logue JP, Swindell R, Cowan RA, Wylie JP, Livsey JE. External-beam radiotherapy in T1-2 NO penile carcinoma. Clin Oncol (R Coll Radiol).2006;18(4):320-325. doi: 10.1016/j.clon.2006.01.004.

21. Smith Y, Hadway P, Biedrzycki O, Perry MJA, Corbishley C, Watkin NA. Reconstructive surgery for invasive squamous carcinoma of the glans penis. Eur Urol.2007:52(4):1179-1185. doi: 10.1016/j. eururo.2007.02.038. Epub 2007 Feb 20.

22. Crook J, Ma C, Grimard L. Radiation therapy in the management of the primary penile tumor: an update. World J Urol.2009;27(2):189-196.

23. Gotsadze D, Matveev B, Zak B, Mamaladze V. Is conservative organ-sparing treatment of penile carcinoma justified? Eur Urol.2000;38(3):306-312. doi: 10.1159/000020298. 
24. Ornellas AA, Kinchin EW, Nóbrega BLB, Wisnescky A, Koifman N, Quirino R. Surgical treatment of invasive squamous cell carcinoma of the penis: Brazilian National Cancer Institute long-term experience. J Surg Oncol.2008;97(6):487-495. doi: 10.1002/jso.20980.

25. Pizzocaro G. Piva L. Adjuvant and neoadjuvant vincristine, bleomycin, and methotrexate for inguinal metastases from squamous cell carcinoma of the penis. Acta Oncol.1988;27(6b):823-824.

26. Leijte JA, Kerst JM, Bais E, Antonini N, Horenblas S. Neoadjuvant chemotherapy in advanced penile carcinoma. Eur Urol.2007;52(2):488-494. doi: 10.1016/j.eururo.2007.02.006. Epub 2007 Feb 14

27. Meijer RP, Boon TA, van Venrooij GE, Wijburg CJ. Longterm follow-up after laser therapy for penile carcinoma. Urology.2007;69(4):759-762. doi: 10.1016/j.urology.2007.01.023.

28. Zou ZJ, Liu Z-H, Tang L-Y, Wang Y-J, Liang J-Y, Zhang R-C, et al. Radiocolloid-based dynamic sentinel lymph node biopsy in penile cancer with clinically negative inguinal lymph node: an updated systematic review and meta-analysis. Int Urol Nephrol.2016;48(12):2001-2013. doi: 10.1007/s11255-016-1405-x. Epub 2016 Aug 30.

29. Hegarty PK, Dinney CP, Pettaway CA. Controversies in ilioinguinal lymphadenectomy. Urol Clin North Am.2010;37(3):421-434.

30. Lughezzani G, Catanzaro M, Torelli T, Piva L, Biasoni D, Stagni S, et al. The relationship between characteristics of inguinal lymph nodes and pelvic lymph node involvement in penile squamous cell carcinoma: a single institution experience. J Urol.2014;191(4):977982. doi: 10.1016/j.juro.2013.10.140. Epub 2013 Nov 18.

31. Noronha V, Patil V, Ostwal V, Tongaonkar H, Bakshi G, Prabhash K, et al. Role of paclitaxel and platinum-based adjuvant chemotherapy in high-risk penile cancer. Urol Ann.2012;4(3):150-153. doi: 10.4103/0974-7796.102659

32. Giannatempo P, Paganoni A, Sangalli L, Colecchia M, Piva L, Torelli MCT, et al. Survival analyses of adjuvant or neoadjuvant combination of a taxane plus cisplatin and 5-fluorouracil (T-PF) in patients with bulky nodal metastases from squamous cell carcinoma of the penis (PSCC): Results of a single high-volume center. J Clin Oncol.2014;32(4,Suppl):377. DOI: 10.1200/jco.2014.32.4_suppl.377.

33. Bandini M, Pederzoli F, Necchi A. Neoadjuvant chemotherapy for lymph node-positive penile cancer: current evidence and knowledge. Curr Opin Urol.2020;30(2):218-222. doi: 10.1097/ MOU.0000000000000719.

34. Kulkarni JN, Kamat MR. Prophylactic bilateral groin node dissection versus prophylactic radiotherapy and surveillance in patients with NO and N1-2A carcinoma of the penis. Eur Urol.1994;26(2):123-128.

35. Graafland NM, Moonen LMF, van Boven HH, van Werkhoven E, Kerst JM, Horenblas S. Inguinal recurrence following therapeutic lymphadenectomy for node positive penile carcinoma: outcome and implications for management. J Urol.2011;185(3):888-893. doi: 10.1016/j.juro.2010.10.059. Epub 2011 Jan 15.

36. Franks KN, Kiran Kancherla, Brinda Sethugavalar, Peter Whelan, Ian Eardley, Anne E Kiltie, et al. Radiotherapy for node positive penile cancer: experience of the Leeds teaching hospitals. J Urol.2011;186(2):524-529. doi: 10.1016/j.juro.2011.03.117. Epub 2011 Jun 22
37. Winters BR, Kearns JT, Holt SK, Mossanen M, Lin DW, Wright JL. Is there a benefit to adjuvant radiation in stage III penile cancer after lymph node dissection? Findings from the National Cancer Database. Urol Oncol.2018;36(3):92.e11-92.e16. doi: 10.1016/j. urolonc.2017.11.005. Epub 2017 Nov 27.

38. Tang DH, Djajadiningrat R, Diorio G, Chipollini J, Ma Z, Schaible $B J$, et al. Adjuvant pelvic radiation is associated with improved survival and decreased disease recurrence in pelvic node-positive penile cancer after lymph node dissection: a multi-institutional study. Urol Oncol.2017;35(10):605.e17-605.e23. doi: 10.1016/j. urolonc.2017.06.001. Epub 2017 Jun 27.

39. Homesley HD, Bundy BN, Sedlis A, Adcock L. Radiation therapy versus pelvic node resection for carcinoma of the vulva with positive groin nodes. Obstet Gynecol.1986;68(6):733-740.

40. Parthasarathy A, Cheung MK, Osann K, Husain A, Teng NN, Berek JS. The benefit of adjuvant radiation therapy in single-node-positive squamous cell vulvar carcinoma. Gynecol Oncol.2006;103(3):1095-9. doi: 10.1016/j.ygyno.2006.06.030.

41. de Vries HM, Ottenhof SR, van der Heijden MS, Pos FJ, Horenblas $S$, Brouwer OR. Management of the penile squamous cell carcinoma patient after node positive radical inguinal lymph node dissection: current evidence and future prospects. Curr Opin Urol.2020; 30(2):223-228. doi: 10.1097/MOU.0000000000000714.

42. Crook J. Radiotherapy approaches for locally advanced penile cancer: neoadjuvant and adjuvant.Curr Opin Urol.2017;27(1):62-67. doi: 10.1097/MOU.0000000000000346.

43. Burt LM, Shrieve DC, Tward JD. Stage presentation, care patterns, and treatment outcomes for squamous cell carcinoma of the penis. Int J Radiat Oncol Biol Phys.2014;88(1):94-100.

44. Ravi R, Chaturvedi HK, Sastry DV. Role of radiation therapy in the treatment of carcinoma of the penis. Br J Urol.1994;74(5):646-651.

45. Demkow T. The treatment of penile carcinoma: experience in 64 cases. Int Urol Nephrol.1999;31(4):525-531.

46. Chen MF, Chen W-C, Wu C-T, Chuang C-K, Ng K-F, Chang JT-C. Contemporary management of penile cancer including surgery and adjuvant radiotherapy: an experience in Taiwan. World $J$ Urol.2004;22(1):60-66.

47. Djajadiningrat RS, Graafland NM, van Werkhoven E, Meinhardt W, Bex A, van der Poel HG, et al. Contemporary management of regional nodes in penile cancer-improvement of survival? J Urol.2014;191(1):68-73. doi: 10.1016/j.juro.2013.07.088.

48. Robinson R, Marconi L, MacPepple E, Hakenberg OW, Watkin N, Yuan $Y$, et al. Risks and benefits of adjuvant radiotherapy after inguinal lymphadenectomy in node-positive penile cancer: a systematic review by the European Association of Urology Penile Cancer Guidelines Panel. Eur Urol.2018;74(1):76-83.

49. Ager M, Njoku K, Serra M, Robinson A, Pickering L, Afshar M, et al. Long-term multicentre experience of adjuvant radiotherapy for pN3 squamous cell carcinoma of the penis. BJU Int.2020 Nov 29; Online ahead of print. doi: 10.1111/bju.15309. 